\title{
Alternative Splicing Coupled Nonsense-Mediated Decay Generates Neuronal Cell Type-Specific Expression of SLM Proteins
}

\author{
Lisa Traunmüller, Caroline Bornmann, and ๑Peter Scheiffele \\ Biozentrum, University of Basel, 4056 Basel, Switzerland
}

The unique physiological and morphological properties of neuronal populations are crucial for the appropriate functioning of neuronal circuits. Alternative splicing represents an attractive mechanism for generating cell type-specific molecular repertoires that steer neuronal development and function. However, the mechanisms that link neuronal identity to alternative splicing programs are poorly understood. We report that cell type-specific, mutually exclusive expression of two alternative splicing regulators, SLM1 and SLM2, in the mouse hippocampus is achieved by a cross-repression mechanism. Deletion of SLM2 in vivo modifies alternative splicing of its paralog Slm1 and stabilizes its mRNA, resulting in expression of SLM1 in previously SLM2-expressing cells. Despite this ectopic upregulation of SLM1, loss of SLM2 severely disrupts the alternative splicing regulation of Nrxn1, Nrxn2, and Nrxn3, highlighting that the two SLM paralogs have partially divergent functions. Our study uncovers a hierarchical, SLM2-dependent mechanism for establishing cell typespecific expression of neuronal splicing regulators in vivo.

Key words: alternative splicing; Cbln; neurexin; neuroligin; plasticity; RNA

\section{Introduction}

The mammalian nervous system consists of a complex network of neuronal cell types, which are defined by unique molecular, physiological, and anatomical properties. Cell type-specific properties rely on gene expression programs that shape protein levels and isoform repertoires, including cell surface receptors, ion channels, signaling, and transport regulators. The transcriptional mechanisms that specify neuronal cell types and guide their growth during early development have been extensively studied (Dasen and Jessell, 2009; Hobert et al., 2010). By comparison, there is a lack of knowledge about cell type-specific gene expression programs associated with neuronal connectivity and function, in particular with respect to the complex recognition events between synaptic partners.

Significant diversification of protein function is achieved at the level of alternative pre-mRNA splicing (Norris and Calarco, 2012; Darnell, 2013; Zheng and Black, 2013). Temporally and spatially controlled alternative splicing programs can direct molecular and, thereby, functional diversity of gene products. More

\footnotetext{
Received Aug. 14, 2014; revised 0ct. 22, 2014; accepted 0ct. 25, 2014.

Author contributions: L.T. and P.S. designed research; L.T. and C.B. performed research; L.T. and P.S. analyzed data; L.T. and P.S. wrote the paper.

This work was supported by the Swiss National Science Foundation, EU-AIMS (which receives support from the Innovative Medicines Initiative Joint Undertaking of the EU FP7) and the Kanton Basel-Stadt to P.S., L.T. was supported by the Erasmus Student Mobility Program. We thank Oriane Mauger, Harald Witte, Le Xiao, and other members of the P.S. laboratory for advice and insightful comments on the manuscript.

The authors declare no competing financial interests.

Correspondence should be addressed to Dr. Peter Scheiffele, Biozentrum, University of Basel, Klingelbergstrasse 50-70, 4056 Basel, Switzerland. E-mail: peter.scheiffele@unibas.ch.

DOI:10.1523/JNEUROSCI.3395-14.2014

Copyright $\odot 2014$ the authors $\quad 0270-6474 / 14 / 3416755-07 \$ 15.00 / 0$
}

recently, alternative splicing-dependent nonsense-mediated mRNA decay (NMD) has emerged as a mechanism for controlling gene expression levels (McGlincy and Smith, 2008; Bicknell et al., 2012). To this end, alternative splicing directs the incorporation of exons, which contain premature translation termination codons, leading to the targeted degradation of the mRNA. Thus, alternative splicing not only contributes to the molecular diversification of gene products but also plays a major role in the regulation of levels and kinetics of protein expression.

A prerequisite for cell type-specific gene regulation through alternative splicing is the selective expression of alternative splicing regulators in defined cell populations. One interesting example are the $\mathrm{KH}$-domain containing RNA-binding proteins Sam68, SLM1, and SLM2 (Sam68-like mammalian proteins), which belong to the STAR (signal transduction and activator of RNA) family. SAM68 (Src-associated substrate in mitosis of 68 $\mathrm{kDa}$ ) is ubiquitously expressed in neuronal and non-neuronal cells, whereas SLM1 and SLM2 exhibit a remarkable, mutually exclusive expression in neuronal cell types (Di Fruscio et al., 1999; Venables et al., 1999; Stoss et al., 2004; Iijima et al., 2011, 2014). Notably, SLM1 and SLM2 are important regulators of neuron-specific alternative splicing, as both proteins repress incorporation of alternative exons at the alternatively spliced segment 4 (AS4) in Nrxn1, Nrxn2, and Nrxn3, a class of synaptic cell surface receptors (Iijima et al., 2011, 2014; Ehrmann et al., 2013). The resulting NRX AS4 protein variants differ in their interactions with cell surface ligands, and disruption of alternative splicing at AS4 results in defects in synapse formation and plasticity (Boucard et al., 2005; Chih et al., 2006; Graf et al., 2006; Aoto et al., 2013). Despite this critical importance of SLM1 and SLM2 function in generating cell type-specific repertoires of NRX iso- 
A

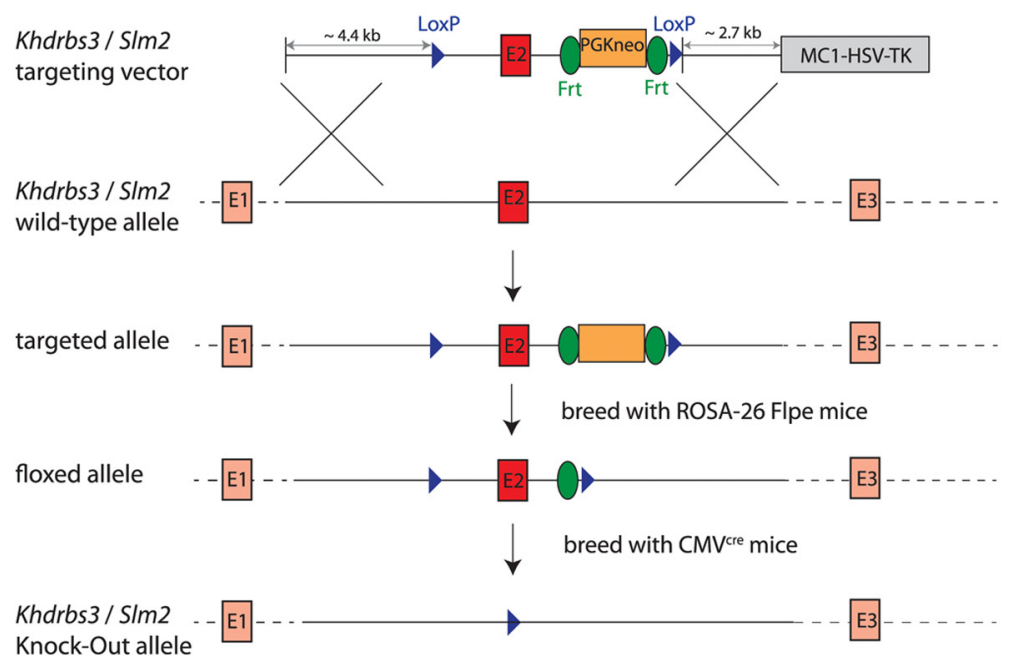

B
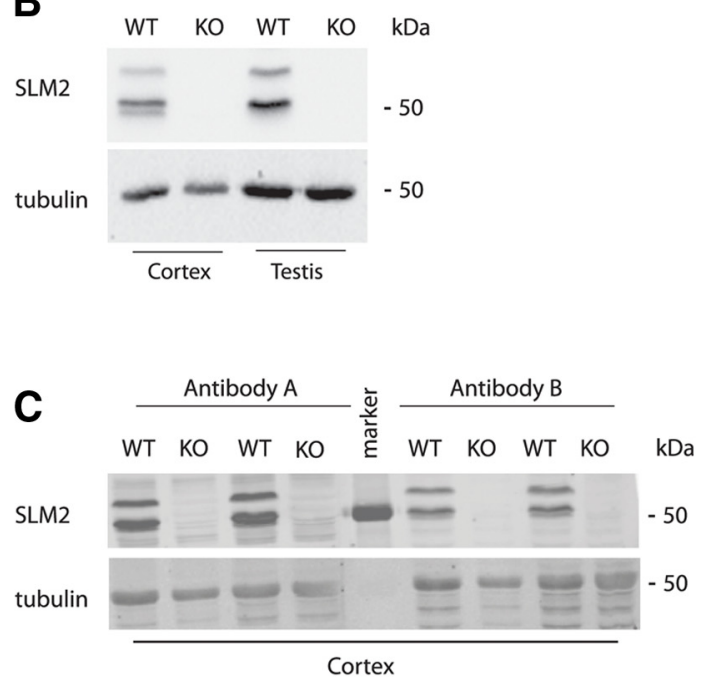

Figure 1. A, Targeting strategy for generation of conditional SIm2 $2^{K O}$ mice. The Khdrbs3 gene encoding SLM2 protein was modified by insertion of LoxP sites (blue) flanking exon 2 (E2) and targeted ES cells isolated based on G418-resistance conferred by the PGKneo cassette (orange). PGKneo was subsequently excised by breeding to ROSA-26 Flpe mice. The S/m2 knock-0ut allele was generated by crossing S/m2 floxed animals with CMV cre delete mice. $\boldsymbol{B}$, Successful ablation of SLM2 was verified by Western blot analysis of cortical and testis tissue. $\boldsymbol{C}$, Western blot analysis of two sets of WT and $\operatorname{SIm} 2^{K O}$ littermates, tested with two different antibodies $(\boldsymbol{A}, \boldsymbol{B})$ against two different epitopes of the SLM2 protein. S/m2 encodes several protein variants detected as bands of different electrophoretic mobility.

forms, the mechanisms underlying the mutually exclusive expression of SLM1 and SLM2 proteins in the mammalian nervous system are unknown.

In this work, we uncover that deletion of $\operatorname{Slm} 2$ in mice results in an unexpected elevation of SLM1 expression, specifically in cells formerly expressing SLM2. In wild-type but not $\operatorname{SIm} 2^{K O}$ neurons, $\operatorname{Slm} 1 \mathrm{mRNA}$ is targeted for NMD by use of a previously uncharacterized splice donor site in the 3'UTR. Ectopic expression of $\operatorname{SIm} 2$ in dentate granule cells of the hippocampus is sufficient to suppress endogenous SLM1 expression. Surprisingly, deletion of $\operatorname{SIm} 2$ alone results in a profound disruption in alternative splicing regulation of $N r x n 1, N r x n 2$, and $N r x n 3$, despite the upregulation of $\operatorname{Slm} 1$. Our study highlights a key function for $S \operatorname{lm} 2$ in neuronal alternative splicing regulation by directing cell type-specific splice variant choices of Nrxns. Moreover, our results provide strong genetic evidence for alternative splicing coupled NMD in instructing cell type-specific gene expression patterns in vivo.

\section{Materials and Methods}

Knock-out mice. $\operatorname{Slm} 1^{K O}$ mice were previously described (Iijima et al., 2014). An Slm2 conditional allele was generated by homologous recombination in mouse embryonic stem cells. Briefly, a genomic DNA fragment containing exon 2 (ENSMUSE00000328887) was flanked by a LoxP site and a FRT-PGK-neo-LoxP cassette encoding neomycin phosphotransferase under the control of the phosphoglycerate kinase 1 promoter. The targeting vector was electroporated into 129SvEvTac embryonic stem cells. Homologous recombination in G-418-resistant clones was confirmed, and selected cells were blastocyst injected. Chimeric animals were crossed with ROSA-26 Flpe mice (Farley et al., 2000) to remove PGK-neo sequences through Frt/Flp-mediated excision. Slm $2^{\text {flox/++}}$ mice were crossed with $\mathrm{CMV}^{\text {cre }}$ deleter mice (Schwenk et al., 1995) to create a germline deletion of exon 2 . The $S \operatorname{lm} 2^{\text {flox }}$ allele was detected by PCR using primers 5'-GCTTTACAGTAGAGAAACTGG-3' (Lox gtF), 5' CATAGATGACCTGCTGTCAG-3' (Lox gtR), 5' -CGGTTGGATGGTATACATGAC-3' (Frt gtF), and 5' -CAATGCTGTTACTCATCAGG-3' (Frt gtR). $\operatorname{Slm} 1: \operatorname{Slm} 2^{D K O}$ mice were generated by intercrossing of the individual mutant mice. The resulting homozygous mice were viable.

Antibodies. Polyclonal antibodies for SAM68, SLM1, and SLM2 were previously described (Iijima et al., 2014). Commercially available antibodies were used: mouse anti- $\beta$-tubulin (E7, DSHB, 1:10000), mouse anti-GFP (Invitrogen, 1:1000), and mouse anti-NeuN (Millipore Bioscience Research Reagents, 1:2000).

Molecular biology procedures. For immunoblotting, either HRPconjugated secondary antibodies and Pierce ECL Western Blotting Substrate or fluorescent IRDye coupled secondaries were used. Signals were acquired using an image analyzer (Bio-Rad, ChemiDoc MP Imaging System and Li-Cor, Odyssey). Dissociated cultures of mouse hippocampal cells were prepared from P0 pups and maintained in Neurobasal medium (Invitrogen ) containing 2\% B27 (Invitrogen) supplement and 2 mm Glutamax (Invitrogen) at $37^{\circ} \mathrm{C}$ and $5 \% \mathrm{CO}_{2}$. Cylcoheximide was applied at a final concentration of $50 \mu \mathrm{g} / \mathrm{ml}$ for $4 \mathrm{~h}$ before harvesting. Total RNA from cultured cells was extracted with Trizol and purified using QIAGEN RNeasy Mini Kit.

Alternative splicing analysis. PCR primer sequences are as follows: Nrxn1 AS4, 5'-TGTTGGGACAGATGACATCGCC-3' and 5'GAGAGCTGGCCCTGGAAGGG-3'; Nrxn2 AS4, 5'GTGCGCTTTACTCGAAGTGGTG3' and 5'CCCATTGTAGTAGAGGCCGGAC3'; Nrxn3 AS4, 5'TTGTGCGCTTCACCAGGAATG3' and 5'AGAGCCCAGAGAGTTGACCTTG3'; Gapdh, 5'GCTTGTCATCAACGGGAAG3' and 5'TTGTCATATTTCTCGTGGTTCA3'; and Slm1 Ex8-Ex9b, 5'CTACGGTCATGGAGTAAACGAG3' and 5' GGGAATACAAGAAATAGTGGGAGC3'; and $\operatorname{Slm} 1$ Ex8-Ex10, 5'CTACGGTCATGGAGTAAACGAG3 and 5'CCCTTTAGGCCATCATATCTGC3'.

Sequences of quantitative PCR primers. Quantitative PCR was performed on a StepOnePlus qPCR system (Applied Biosystems). Gene expression assays were used with TaqMan Master Mix (Applied Biosystems) or Power SYBR Green Master Mix (Applied Biosystems) and comparative $\mathrm{C}_{\mathrm{T}}$ method. The cDNA levels were normalized to Gapdh cDNA.

Commercially available gene expression assays for Gapdh (Mm99999915g1), Nrxn1 (Mm00660298_m1), Nrxn2 (Mm01236851_ m1), and Nrxn3 (Mm00553213_m1) were from Applied Biosystems; and assays for $\operatorname{Slm} 1$ (Mm.PT.58.41510930) and Slm2 (Mm.PT.58.10822025) were from Integrated DNA Technologies. Custom gene expression assays to interrogate Nrxn splicing at AS4 were previously described (Iijima et al., 2014).

Primer sequences used with Power SYBR Green PCR Mastermix were as follows: $\operatorname{Sim} 1$ Ex3-Ex4, 5'-GACCAAGAGGAAACTCCTTGAA-3' and 
A

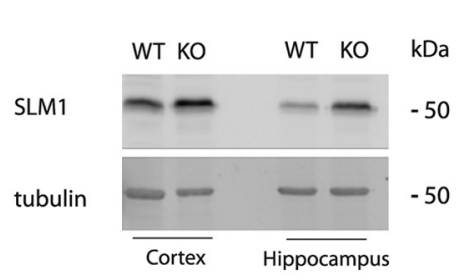

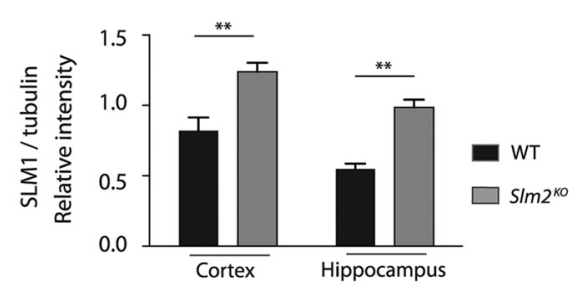

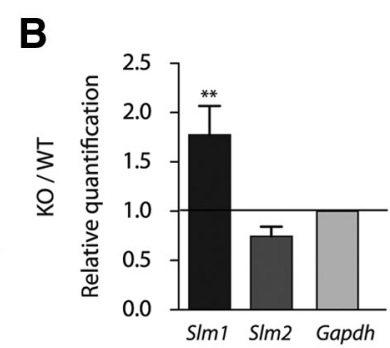

Figure 2. $\quad \boldsymbol{A}$, Upregulation of SLM1 in different brain regions in $S / m 2^{K O}$ mice (left). Quantification of SLM1/tubulin ratios in WT and SIm2 $2^{K O}$ mice of the hippocampus and cortex (right) $(n=4$ animals, 8 weeks old). ${ }^{* *} p<0.01$. B, Quantitative RT-PCR for total $S / m 1$ and $S / m 2$ mRNA of hippocampal tissue. WT mRNA/Gapdh values were set to 1.0 and compared with $\operatorname{SIm} 2^{K O}$ values $(n=4$ animals, 8 weeks old).

A
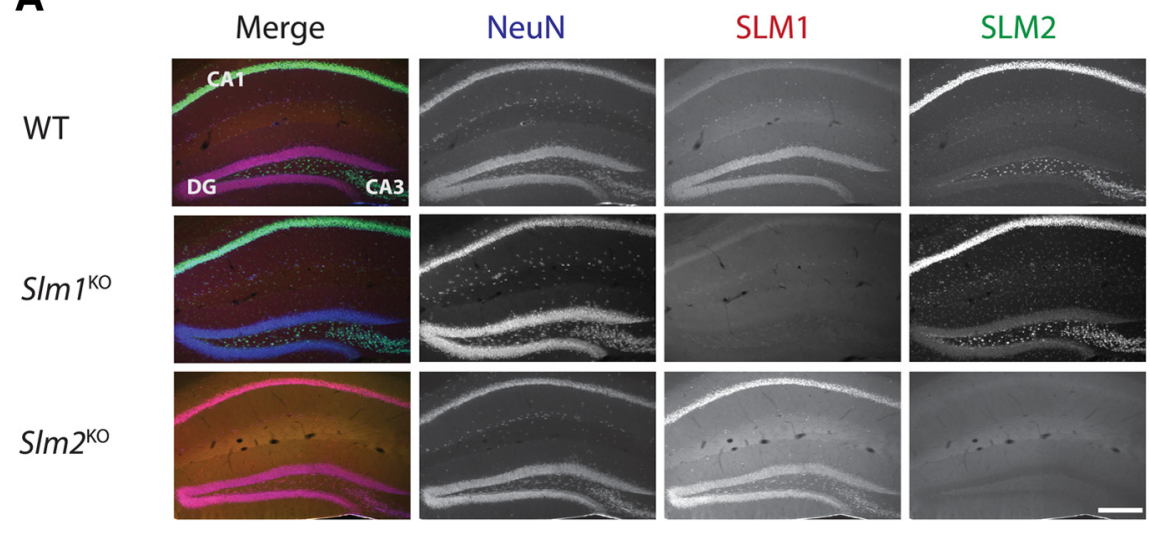

B

DG

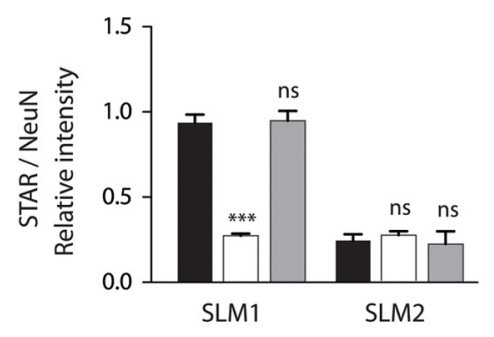

CA1

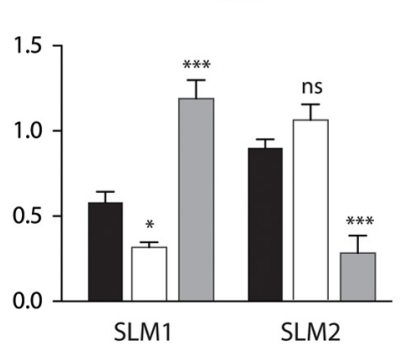

CA3

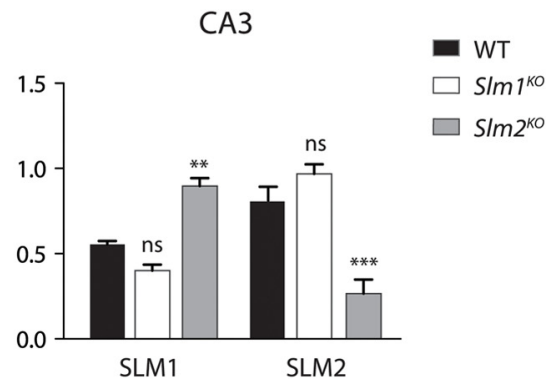

Figure 3. A, Hippocampal sections of WT, $\operatorname{S} / m 2^{\mathrm{K} 0}$, and $\operatorname{SIm} 1^{\mathrm{K} 0}$ mice were stained for the neuronal marker NeuN, as well as for SLM1 and SLM2. Scale bar, $200 \mu \mathrm{m}$. $\boldsymbol{B}$, Quantification of mean intensities of SLM1 and SLM2 in DG, CA1, and CA3 areas for $S / m 1^{K O}$ and $S / m 2^{K O}$ animals ( $n=4$ animals, 3 months of age, 2 sections per animal were used). Relative values compared with NeuN are plotted. ns, Not significant $(p>0.05) .{ }^{*} p<0.5 .{ }^{* *} p<0.01 .{ }^{* *} p<0.001$. These values are the raw fluorescent values without background subtraction. The K0 genotypes serve as an indication of respective background labeling.

5'-GGCATGACTCATCCGTGAATA-3; $\operatorname{Slm} 1$ Ex8-9a, 5'-GTGCCTGAATACTATGACTACGG-3' and $5^{\prime}$-GAGACCACAGGCTATGAA TTGT3'; $\operatorname{Slm} 1$ Ex9a-9b, 5'-CATCTGTGACCTCCTCAAAGAC-3' and 5'-TGTCCACGTCACATTAACAGTAT-3'; and Slm 1 Ex9a-10, 5'CATCTGTGACCTCCTCAAAGAC-3' and 5'-CCCTTTAGGCCAT CATATCTGC-3'.

Immunohistochemistry, image acquisition, and statistical analysis. Animals (male and female) were transcardially perfused with fixative (4\% $\mathrm{PFA} / 15 \%$ picric acid in $100 \mathrm{~mm}$ phosphate buffer, $\mathrm{pH}$ 7.2). Tissue was sectioned at $50 \mu \mathrm{m}$ in PBS on a vibratome (VT1000S, Leica), and floating sections were immunostained following standard procedures. Images were acquired at room temperature on an inverted LSM700 confocal microscope (Zeiss) using $10 \times$ and $63 \times$ Apochromat objectives and controlled by Zen 2010 software. Images were assembled using Adobe Photoshop and Illustrator software. For quantitative assessment of protein upregulation or downregulation, ImageJ was used. Statistical analysis was done with Prism software (GraphPad software). All statistical data are mean \pm SEM. Data were tested for normality using ANOVA and Bonferroni's or Dunnett's post hoc test for multiple comparisons.
All procedures related to animal experimentation were reviewed and approved by the Kantonales Veterinäramt Basel-Stadt.

Adeno-associated virus (AAV) production. Viral supernatants were produced by cotransfection of HEK293T cells with a mixture of three plasmids. The plasmid mixture consisted of $70 \mu \mathrm{g}$ of AAV helper plasmid (Rep/Cap, Serotype II), $200 \mu$ g of AAV pHGTI-adenol (Plasmid Factory), and $70 \mu \mathrm{g}$ of vector plasmid Synapsin-SLM2-2A-Venus or Synapsin-EGFP (containing the human synapsin promoter). At 45-60 h after transfection, medium containing viral particles was harvested and purified using the Iodixanol purification method. The fraction samples were dialyzed and concentrated in Millipore Amicon $100 \mathrm{~K}$ columns, washed $3 \times$ with $\mathrm{PBS}$, and centrifuged at $3500 \mathrm{rpm}$ at $4^{\circ} \mathrm{C}$. Viruses were frozen in aliquots and stored at $-80^{\circ} \mathrm{C}$. Viruses were delivered by stereotaxic injection at postnatal day 8 into the dentate gyrus (DG) of the mouse hippocampus. Infected cells were marked by EGFP expression from the same vector. Animals were transcardially perfused at postnatal day 40 , and $50-\mu \mathrm{m}$-thick vibratome slices were analyzed by immunohistochemistry. 
A

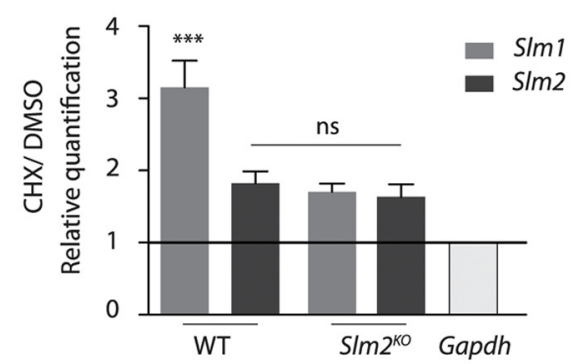

C

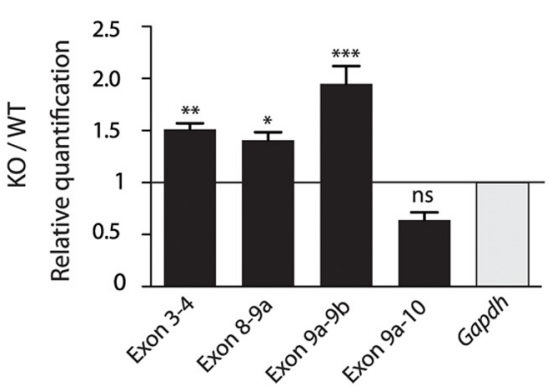

B

SIm 1 transcript 1

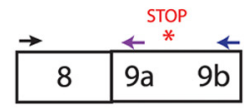

Chromosome 1 GRCm38/mm10

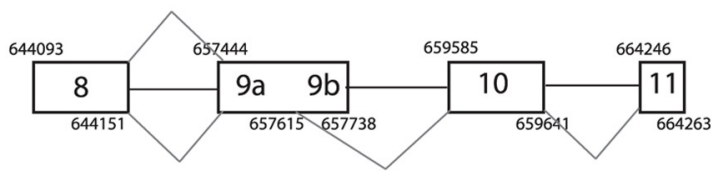

S $/ m 1$ transcript 2 (XR_373243.1)

D

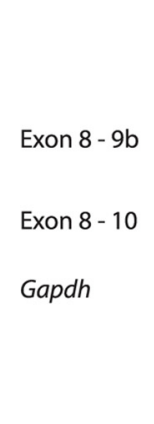

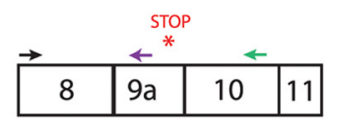

E

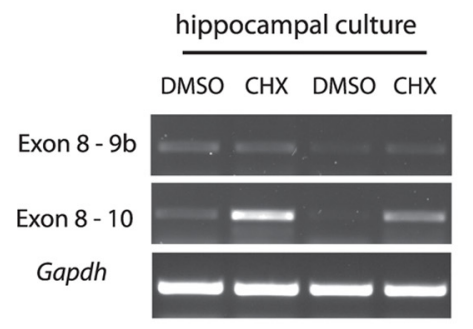

Figure 4. A, Quantitative RT-PCR for total $S / m 1$ and SIm2 mRNA. Mouse hippocampal cultures were treated at day in vitro 7 for $4 \mathrm{~h}$ either with the translation blocker cycloheximide (CHX) or DMSO ( $n=3$ independently generated cultures). WT mRNA/Gapdh values in DMSO-treated control cells were set to 1.0 and compared with cells treated with CHX. There is a significant upregulation of $S / m 1$ in the WT when treated with CHX; however, there is no upregulation of either $\operatorname{SIm} 1$ or $S / m 2$ in the $S / m 2^{K O}$. ns, Not significant $(p>0.05) .{ }^{* * *} p<0.001$. B, Schematic representation of incorporation of exon 10 and exon 11 and primer binding sites for quantitative RT-PCR. Chromosome coordinates are taken from USCS Genome Browser (release date reference GRCm38/mm10). All chromosome coordinates start with 3217. C, Quantitative RT-PCR for increases in $\operatorname{SIm} 1$ transcripts at various exons comparing WT and $\operatorname{SIm} 2^{K O}$ animals ( $n=4$ animals, 8 weeks old). ns, Not significant ( $p>0.05$ ). ${ }^{*} p<0.5 .{ }^{* *} p<0.01 .{ }^{* * *} p<0.001$. For the quantitative RT-PCR, primer sets flanking from exon 9a onwards instead of exon 8 were used because of the sizes of the exons. $D$, Exon spanning RT-PCR of WT and S/m2 ${ }^{\mathrm{K} 0}$ animals. E, The transcript targeted for NMD (Ex8 -10) is stabilized in wild-type animals when treated with CHX.

\section{Results}

\section{Ablation of SIm2 in vivo results in elevated expression} of $\operatorname{Slm} 1$

To explore functions of the RNA-binding protein SLM2 in vivo, a novel mouse knock-out $\operatorname{Slm} 2$ allele was created in which exon 2 of the mouse Khdrbs3 gene (which encodes for SLM2) was flanked by LoxP sites. Global $\operatorname{Sim} 2^{K O}$ mice were generated by cremediated recombination in the germline. Removal of exon 2 introduces multiple premature stop codons and disrupts the $\operatorname{SIm} 2$ open reading frame (Fig. 1A). SLM2 is mainly expressed in the brain and in testis (Stoss et al., 2004; Venables et al., 2004); we thus investigated loss of SLM2 in these body regions (Fig. 1B). Additionally, Western blotting analysis with two SLM2-specific antibodies directed against different epitopes further confirmed that $\operatorname{Slm} 2^{K O}$ mice lacked detectable SLM2 protein expression (Fig. 1C). $\operatorname{Stm} 2^{K O}$ mice were viable and fertile and did not exhibit obvious behavioral abnormalities, as previously reported for a different $\operatorname{SIm} 2^{K O}$ allele (Ehrmann et al., 2013).

Upregulation of SLM1 in previously SLM2-positive cells

Surprisingly, we detected a 2.5-fold upregulation of SLM1 protein levels in hippocampus and cortex of $\operatorname{Sim} 2^{K O}$ mice (Figure $2 A$; one-way ANOVA with Bonferroni post hoc test, $p<0.01$ ). A significant increase was also detected for $\operatorname{SIm} 1$ mRNA in the hippocampus of $\operatorname{Slm} 2^{K O}$ mice (Fig. $2 B$; one-way ANOVA with Bonferroni post hoc test, $p<0.01$ ). By contrast, no alterations were observed for the closely related RNA-binding protein SAM68 (data not shown). To explore whether SLM1 is globally elevated or whether its upregulation is restricted to specific cell populations, we performed detailed immunohistochemical analysis using SLM1- and SLM2-specific antibodies. Principal cells in the mature hippocampus exhibit a remarkable, cell type-specific expression pattern of SLM1 and SLM2: SLM1 is expressed in dentate granule cells, and a specific subgroup of inhibitory interneurons, however, is absent from the cornus ammonis-1 (CA1) and CA3 pyramidal cells. By contrast, SLM2 is highly expressed in the CA1 and CA3 pyramidal cells and a different set of interneurons, but not detectable in the DG (Stoss et al., 2004; Iijima et al., 2014) (Fig. $3 A$, top). In $\operatorname{SIm} 2^{K O}$ mice, SLM1 was significantly upregulated in CA 1 and CA3, whereas expression in DG was unchanged (Fig. $3 A, B$; two-way ANOVA with Bonferroni post hoc test). Thus, in the absence of SLM2, formerly SLM2-positive cells selectively turn on SLM1 expression. This suggests that the mutually exclusive expression pattern of SLM1 and SLM2 in neuronal populations might be achieved through cross-repression of SLM1 by SLM2. Interestingly, we did not detect an analogous upregulation of SLM2 in the DG of $\operatorname{Slm} 1^{K O}$ mice (Fig. $3 A, B$ ). These findings suggest that SLM2 is required for spatially restricting SLM1 expression in a unidirectional manner.

\section{$\operatorname{Slm} 2$ is required and sufficient to establish the mutually exclusive expression pattern of SLM proteins}

Considering that SLM2 is an RNA-binding protein, we hypothesized that it may suppress $\operatorname{SIm} 1$ expression by targeting $\operatorname{Sim} 1$ mRNA for NMD in wild-type animals. To test this possibility, we 
A

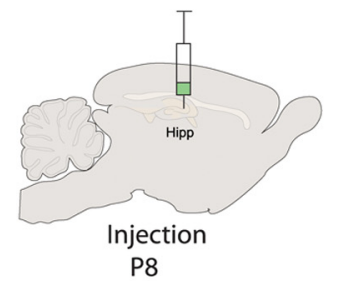

B
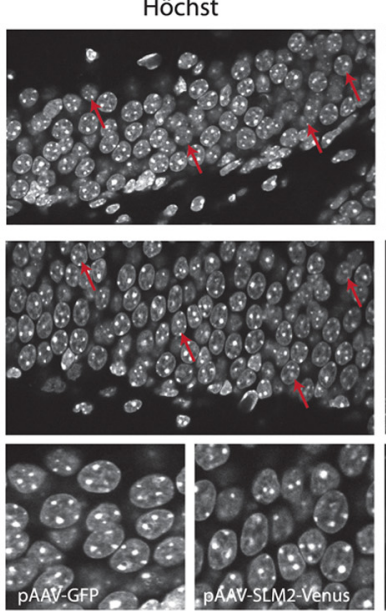

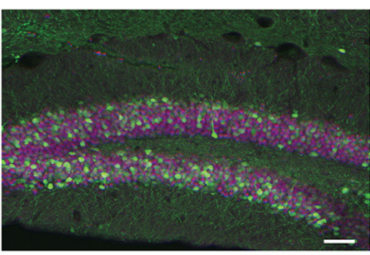

$\longrightarrow \begin{gathered}\text { Analysis } \\ \text { P40 }\end{gathered}$
EGFP

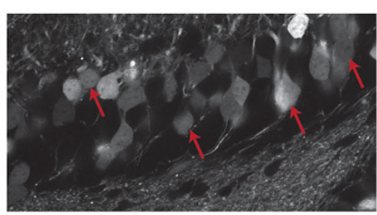

SLM1

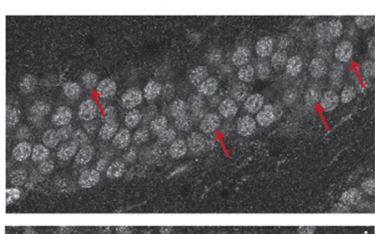

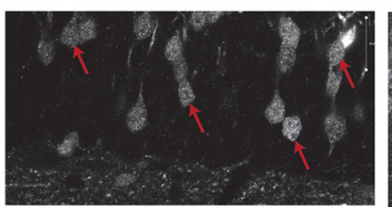
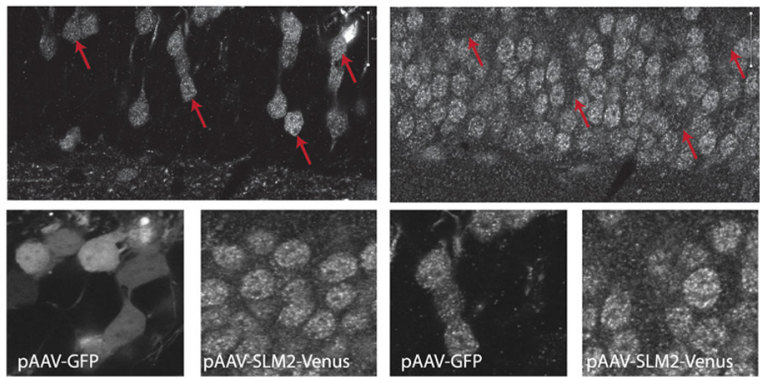
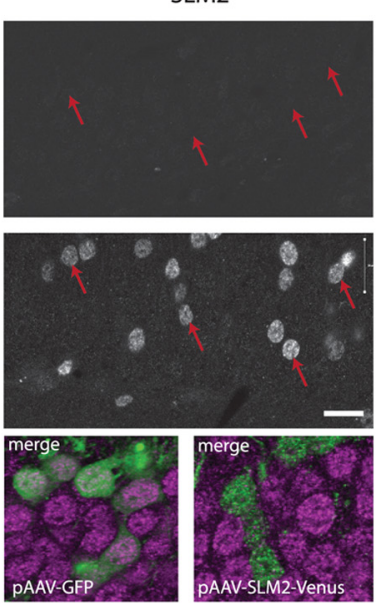

Figure 5. A, Injection of AAV-viruses into the DG of WT animals at postnatal day 8 (P8). Mice were analyzed at P40. Scale bar, $100 \mu \mathrm{m}$. $\boldsymbol{B}$, Immunohistochemistry analysis of WT animals injected either with pAAV-EGFP, as injection control, or pAAV-SLM2-Venus. Sections were stained for the nucleic acid stain Hoechst, and antibodies against EGFP, SLM1, and SLM2. Scale bar, $50 \mu \mathrm{m}$. Bottom, Higher-magnification views of fields from the overview panels. Color code for merge is GFP (green) and SLM1 (magenta).

treated cultured wild-type and $\operatorname{Slm} 2^{K O}$ hippocampal neurons with cycloheximide (CHX), an inhibitor of protein translation. As NMD depends on active translation, transcripts that are subject to NMD are stabilized upon translational arrest (Carter et al., 1995). Slm 1 transcript levels increased threefold upon CHX treatment of wild-type neurons. (Fig. 4A; one-way ANOVA with Bonferroni post hoc test). Importantly, in $\operatorname{Slm} 2^{K O}$ cultures, $\operatorname{Sim} 1$ transcript levels were not further increased after CHX treatment (Fig. 4A; one-way ANOVA with Bonferroni post hoc test, not significant, $p>0.05$ ).

In the same experiment, $\mathrm{CHX}$ treatment appears to slightly elevate $\operatorname{Slm} 2$ transcripts in wild-type and $\operatorname{Slm} 2^{K O}$ neurons (Fig. $4 A$ ), although this trend did not reach statistical significance.

These findings are consistent with NMD of $\operatorname{Stm} 1$ mRNA through a process that requires $\operatorname{Slm} 2$. One possible mechanism of how SLM2 could target Slm1 mRNA for NMD would be the incorporation of alternative exon sequences through regulated alternative splicing that attract exon junction complexes downstream of the stop codon in $\operatorname{Slm} 1$ transcripts. Through database searches, we identified a previously uncharacterized potential splice donor site in exon9 of $\operatorname{Slm} 1$, which would link two additional exons encoding the $3^{\prime}$ UTR (exons 10 and 11; Fig. 4B). We hypothesized that an SLM2-driven alternative splicing event might promote incorporation of these exons. To test this possibility, we performed exon-spanning RT-PCRs for the presumptive exon 10 in the $3^{\prime}$ UTR. We used primer sets binding upstream and downstream of the potential internal splice donor site flanking various exons of the $\operatorname{Slm} 1$ transcript (Fig. 4B). We could confirm the novel transcript 2 variant linking exon 8 and exon 10 (PCR products exons 8-10), representing the $\operatorname{Slm} 1$ variant containing a $3^{\prime}$ UTR intron, predicted to undergo NMD (Fig. $4 D)$. In $\operatorname{Slm} 2^{\mathrm{KO}}$ mice, we observed an increase in the alternative transcript 1 variant containing exon $8-9 b$ both with RT-PCR and quantitative RT-PCR, confirming that the presence of SLM2 suppresses formation of this (stable) form of $S \operatorname{lm} 1 \mathrm{mRNA}$ (Fig. 4C,D; Dunnett's multiple comparison test). Using primer pairs upstream of the internal splice donor site (exons 3 and 4, exons 8 and 9a), we further confirmed that the whole $\operatorname{Slm} 1$ transcript was stabilized (Fig. 4C). Products containing exons 8-10 showed a trend to decrease in $\operatorname{Slm} 2^{K O}$ cells (Fig. $4 C$ ). However, if these mRNAs are indeed targeted for translation-dependent decay, this is difficult to quantify. To further explore this possibility, we performed CHX treatment of wild-type hippocampal neurons. Exons 8-10-containing transcripts were significantly increased in CHX-treated cells, consistent with the hypothesis that they are targeted for NMD (Fig. 4E).

If $\operatorname{Slm} 2$ indeed targets $\operatorname{Slm} 1$ mRNA for degradation, then $S \operatorname{lm} 2$ should be sufficient to suppress SLM1 expression when introduced into SLM1-positive cell populations. AAV-mediated SLM2 mis-expression in the DG of the mouse hippocampus in vivo abolished SLM1 expression in dentate granule cells (Fig. $5 A, B$ ). SLM2 was introduced into the DG at postnatal day 8 (P8), and mis-expressing neurons were viable and developed apparently normal axonal and dendritic processes when analyzed at P40. However, their cell nuclei were devoid of SLM1 protein. Thus, SLM2 is required and sufficient to regulate the cell typespecific expression of SLM proteins in vivo.

\section{Alternative splicing regulation in $\operatorname{Slm} 1: \operatorname{Slm} 2^{D K O}$ mice}

SLM1 and SLM2 have partially overlapping targets; however, they are expressed in largely nonoverlapping cell populations (Stoss et al., 2004; Iijima et al., 2014). Thus, the upregulation of SLM1 in $\operatorname{Slm} 2^{K O}$ neurons needs to be considered when interpreting loss-of-function phenotypes. We set out to determine the impact of $\operatorname{Slm} 1$ and $\operatorname{Slm} 2$ loss-of-function in $\operatorname{Slm} 1: \operatorname{Slm} 2^{D K O}$ mice. $\operatorname{Slm} 1: \operatorname{Slm} 2^{D K O}$ mice were born at Mendelian frequencies and 
A

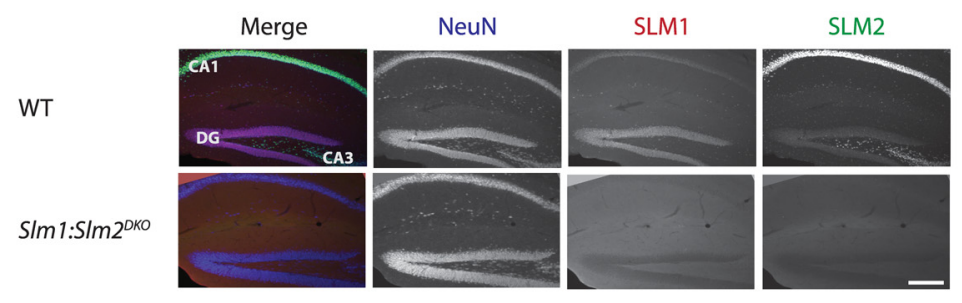

B

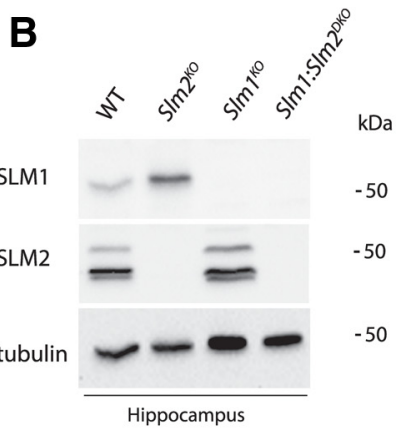

C

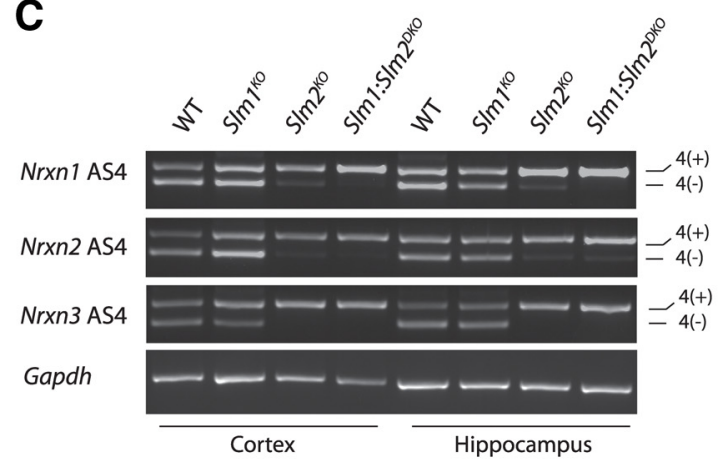

D

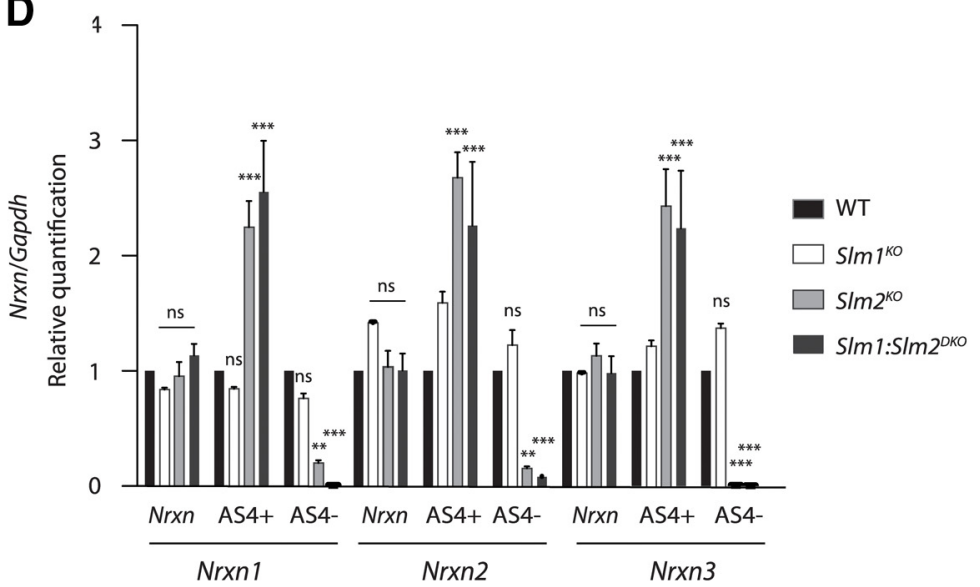

Figure 6. $\quad A$, Loss of SLM1 and SLM2 expression in the SIm1:SIm2 ${ }^{D K O}$ was verified by SLM1 and SLM2-specific immunostaining. Scale bar, $200 \mu \mathrm{m}$. B, Loss of SLM1 and SLM2 expression verification in the $\operatorname{SIm} 1^{K O}, \operatorname{SIm} 2^{K O}$, and $\operatorname{SIm} 1: S \operatorname{Im} 2^{2 K O}$ by Western blotting analysis. Two gels were loaded with equal amounts of sample for the individual genotypes; however, the tubulin control displayed derived from the gel also probed for SLM1. C, Representative images of semiquantitative RT-PCR with Nrxn AS4 in cortex and hippocampus from WT, $\operatorname{SIm} 7^{K 0}, \operatorname{SIm} 2^{\mathrm{K} 0}$, and $\operatorname{SIm} 1: S / m 2^{D K 0}$ mice. D, Quantitative RT-PCR for Nrxn1, Nrxn2, and Nrxn3 AS4 variants in hippocampal tissue. Total Nrxn1, Nrxn2, and Nrxn3 levels are unchanged in the $\operatorname{SIm} 7^{\mathrm{KO}}\left(n=3\right.$ animals), $\operatorname{SIm} 2^{\mathrm{KO}}(n=4$ animals), and $\operatorname{SIm} 1: \operatorname{SIm} 2^{\mathrm{DKO}}\left(n=3\right.$ animals). For $\operatorname{SIm} 2^{K O}$ and SIm 1:SIm2 ${ }^{\text {KKO }}$, significant upregulation could be detected for Nrxn1, Nrxn2, and Nrxn3 AS4(+) and corresponding downregulation of Nrxn1, Nrxn2, and $\operatorname{Nrxn3} \mathrm{AS4}(-)$, respectively. In hippocampus, the $S / m 7^{K 0}$ did not display any changes for all three Nrxn genes at AS4 compared with WT animals. ns, Not significant $(p>0.05)$. ${ }^{* *} p<0.01$. ${ }^{* * *} p<0.001$.

were viable. Successful ablation of SLM1 and SLM2 was verified by immunohistochemistry (Fig. 6A) and Western blotting analysis (Fig. $6 B$ ). $S \operatorname{lm} 1^{K O}$ as well as $\operatorname{Slm} 2^{K O}$ neurons fail to direct exon skipping of Nrxn1-3 at AS4, which correlates with their regional expression in the brain (Ehrmann et al., 2013, Iijima et al., 2014). To explore how simultaneous loss of both RNA binding proteins affects neuronal alternative splicing regulation, we examined the $\operatorname{Nrxn}$ AS4 regulation in the $\operatorname{SIm} 1^{K O}, \operatorname{SIm} 2^{K O}$, and $\operatorname{SIm} 1: \operatorname{Slm} 2^{D K O}$ mice. Analysis of cortical and hippocampal tissue revealed that splicing patterns were altered for all three Nrxn genes. Expression of AS4 (-) forms was significantly reduced in $\operatorname{Slm} 2^{K O}$ and completely abolished in the $\operatorname{SIm} 1: \operatorname{SIm} 2^{D K O}$. By contrast, the splicing patterns in the $\operatorname{SIm} 1^{K O}$ cortex and hippocampus remained unchanged (Fig. 6C,D). Quantitative RT-PCR revealed that overall Nrxn1, Nrxn2, and Nrxn3 levels were unaltered in all three mutants and confirmed a striking increase of AS4 (+) in Nrxn1-3 for the $\operatorname{Slm} 2^{K O}$ and the $\operatorname{Slm} 1: \operatorname{Slm} 2^{D K O}$ (Fig. 6D; two-way ANOVA). Notably, there was a significant loss of Nrxn AS4- splice isoforms in $\operatorname{SIm} 2^{K O}$ hippocampus, despite the substantial upregulation of SLM1 in SLM2-deficient cells. Thus, in vivo, SLM1 upregulation cannot significantly compensate for loss of SLM2, at least with respect to alternative splicing regulation of Nrxns at AS4.

\section{Discussion}

In mammals, regulated alternative splicing events are widespread; however, the factors underlying the generation of neuronal cell type-specific alternative patterns are poorly understood.
The ability of alternative splicing to generate mRNA isoforms that are targeted for NMD extends the functional impact of alternative splicing regulation from the generation of multiple isoforms derived from a single gene to the spatial and temporal control of transcript levels. In this study, we set out to uncover in vivo functions of SLM2 in neurons and identified an unexpected role in setting up the mutually exclusive expression of SLM1 and SLM2 paralogs in neuronal cell types.

We observed that SLM2 itself is required and sufficient for the mututally exclusive expression of SLM1 and SLM2 in genetically and anatomically defined populations of neurons in the mouse hippocampus. SLM2 promotes the incorporation of an alternative splice donor in the last coding exon of the $\operatorname{Sim} 1$ transcript. Notably, transcripts with 3'UTR introns have long been considered to be erroneous predictions as the resulting mRNAs would be predicted to be NMD substrates. However, recent studies have highlighted unexpected functions of some of these transcripts (Bicknell et al., 2012). We identified one such transcript containing a 3'UTR intron for Slm1. Our genetic gain- and loss-offunction analysis in mice demonstrates that this mRNA is indeed produced through SLM2-dependent alternative splicing and that the resulting destabilization of the alternative $\operatorname{Slm} 1$ transcript represents a fundamental mechanism underlying the neuronal cell type-specific expression of SLM1 protein in vivo.

Previous studies performed largely in cell lines demonstrated that splicing regulators are able to control their own expression 
by producing splice isoforms of their own mRNA that are targeted for NMD (Lareau et al., 2007; Ni et al., 2007). Further studies identified cross-regulation between paralogs of alternative splicing regulators, such as PTBP1 (polypyrimidine-tractbinding protein 1) and PTBP2 (Boutz et al., 2007; Spellman et al., 2007), to shift the alternative splicing patterns from precursors to postmitotic neurons during differentiation and maturation in development. Our results identify a similar cross-repression mechanism for SLM1 and SLM2 to generate a highly spatially restricted pattern of SLM paralogs in specific neuronal populations. SAM68, SLM1, and SLM2 bind similar RNA sequence motifs (Galarneau and Richard, 2009) and appear to regulate some common targets. However, these proteins also exhibit certain isoform-specific properties, including differential regulation by kinases and selective association with additional alternative splicing factors, which results in differential splicing activities (Stoss et al., 2004; Iijima et al., 2011, 2014). Thus, SAM68 requires activation through calcium/CaMK4 signaling to modify alternative splice isoform choices of Nrxns, whereas SLM1 and SLM2 seem to be constitutively active in a cell type-specific manner. In the midbrain, where SLM1 is highly expressed, Nrxn alternative splicing at AS4 is significantly altered in $\operatorname{Slm} 1^{K O}$ mice (Iijima et al., 2014). By contrast, in the hippocampus where SLM1 protein levels are lower, its deletion has little impact on Nrxn1, Nrxn2, and Nrxn3 AS4 regulation. Possible explanations of why neither SAM68 nor SLM1 rescued the splicing phenotype observed in $\operatorname{Slm} 2^{K O}$ cells include that these cells lack signaling-dependent activation or cofactors for SAM68 or SLM1 function, respectively.

Our work uncovers a mechanism underlying the mutually exclusive, cell type-specific expression pattern of STAR proteins in the mammalian brain. Loss of $\operatorname{Stm} 2$ function results in the production of Nrxn variants with altered affinity for their synaptic binding partners (Boucard et al., 2005; Chih et al., 2006; Baudouin and Scheiffele, 2010; Uemura et al., 2010). Further studies will be needed to determine the impact of $\operatorname{Sim} 2$-dependent alternative splicing with regards to changes in synaptic connectivity.

\section{References}

Aoto J, Martinelli DC, Malenka RC, Tabuchi K, Südhof TC (2013) Presynaptic neurexin-3 alternative splicing trans-synaptically controls postsynaptic AMPA receptor trafficking. Cell 154:75-88. CrossRef Medline

Baudouin S, Scheiffele P (2010) SnapShot: neuroligin-neurexin complexes. Cell 141:908. CrossRef Medline

Bicknell AA, Cenik C, Chua HN, Roth FP, Moore MJ (2012) Introns in UTRs: why we should stop ignoring them. Bioessays 34:1025-1034. CrossRef Medline

Boucard AA, Chubykin AA, Comoletti D, Taylor P, Südhof TC (2005) A splice code for trans-synaptic cell adhesion mediated by binding of neuroligin 1 to alpha- and beta-neurexins. Neuron 48:229-236. CrossRef Medline

Boutz PL, Stoilov P, Li Q, Lin CH, Chawla G, Ostrow K, Shiue L, Ares M Jr, Black DL (2007) A post-transcriptional regulatory switch in polypyrimidine tract-binding proteins reprograms alternative splicing in developing neurons. Genes Dev 21:1636-1652. CrossRef Medline

Carter MS, Doskow J, Morris P, Li S, Nhim RP, Sandstedt S, Wilkinson MF (1995) A regulatory mechanism that detects premature nonsense codons in T-cell receptor transcripts in vivo is reversed by protein synthesis inhibitors in vitro. J Biol Chem 270:28995-29003. CrossRef Medline

Chih B, Gollan L, Scheiffele P (2006) Alternative splicing controls selective trans-synaptic interactions of the neuroligin-neurexin complex. Neuron 51:171-178. CrossRef Medline
Darnell RB (2013) RNA protein interaction in neurons. Annu Rev Neurosci 36:243-270. CrossRef Medline

Dasen JS, Jessell TM (2009) Hox networks and the origins of motor neuron diversity. Curr Top Dev Biol 88:169-200. CrossRef Medline

Di Fruscio M, Chen T, Richard S (1999) Characterization of Sam68-like mammalian proteins SLM- 1 and SLM-2: SLM-1 is a Src substrate during mitosis. Proc Natl Acad Sci U S A 96:2710-2715. CrossRef Medline

Ehrmann I, Dalgliesh C, Liu Y, Danilenko M, Crosier M, Overman L, Arthur HM, Lindsay S, Clowry GJ, Venables JP, Fort P, Elliott DJ (2013) The tissue-specific RNA binding protein T-STAR controls regional splicing patterns of neurexin pre-mRNAs in the brain. PLoS Genet 9:e1003474. CrossRef Medline

Farley FW, Soriano P, Steffen LS, Dymecki SM (2000) Widespread recombinase expression using FLPeR (flipper) mice. Genesis 28:106-110. CrossRef Medline

Galarneau A, Richard S (2009) The STAR RNA binding proteins GLD-1, QKI, SAM68 and SLM-2 bind bipartite RNA motifs. BMC Mol Biol 10:47. CrossRef Medline

Graf ER, Kang Y, Hauner AM, Craig AM (2006) Structure function and splice site analysis of the synaptogenic activity of the neurexin-1 beta LNS domain. J Neurosci 26:4256-4265. CrossRef Medline

Hobert O, Carrera I, Stefanakis N (2010) The molecular and gene regulatory signature of a neuron. Trends Neurosci 33:435-445. CrossRef Medline

Iijima T, Wu K, Witte H, Hanno-Iijima Y, Glatter T, Richard S, Scheiffele P (2011) SAM68 regulates neuronal activity-dependent alternative splicing of neurexin-1. Cell 147:1601-1614. CrossRef Medline

Iijima T, Iijima Y, Witte H, Scheiffele P (2014) Neuronal cell type-specific alternative splicing is regulated by the $\mathrm{KH}$ domain protein SLM1. J Cell Biol 204:331-342. CrossRef Medline

Lareau LF, Inada M, Green RE, Wengrod JC, Brenner SE (2007) Unproductive splicing of SR genes associated with highly conserved and ultraconserved DNA elements. Nature 446:926-929. CrossRef Medline

McGlincy NJ, Smith CW (2008) Alternative splicing resulting in nonsensemediated mRNA decay: what is the meaning of nonsense? Trends Biochem Sci 33:385-393. CrossRef Medline

Ni JZ, Grate L, Donohue JP, Preston C, Nobida N, O’Brien G, Shiue L, Clark TA, Blume JE, Ares M Jr (2007) Ultraconserved elements are associated with homeostatic control of splicing regulators by alternative splicing and nonsense-mediated decay. Genes Dev 21:708-718. CrossRef Medline

Norris AD, Calarco JA (2012) Emerging roles of alternative pre-mRNA splicing regulation in neuronal development and function. Front Neurosci 6:122. CrossRef Medline

Schwenk F, Baron U, Rajewsky K (1995) A cre-transgenic mouse strain for the ubiquitous deletion of loxP-flanked gene segments including deletion in germ cells. Nucleic Acids Res 23:5080-5081. CrossRef Medline

Spellman R, Llorian M, Smith CW (2007) Crossregulation and functional redundancy between the splicing regulator PTB and its paralogs $\mathrm{NPTB}$ and ROD1. Mol Cell 27:420-434. CrossRef Medline

Stoss O, Novoyatleva T, Gencheva M, Olbrich M, Benderska N, Stamm S (2004) p59(fyn)-mediated phosphorylation regulates the activity of the tissue-specific splicing factor rSLM-1. Mol Cell Neurosci 27:8-21. CrossRef Medline

Uemura T, Lee SJ, Yasumura M, Takeuchi T, Yoshida T, Ra M, Taguchi R, Sakimura K, Mishina M (2010) Trans-synaptic interaction of GluR $\delta 2$ and Neurexin through Cbln1 mediates synapse formation in the cerebellum. Cell 141:1068-1079. CrossRef Medline

Venables JP, Vernet C, Chew SL, Elliott DJ, Cowmeadow RB, Wu J, Cooke HJ, Artzt K, Eperon IC (1999) T-STAR/ETOILE: a novel relative of SAM68 that interacts with an RNA-binding protein implicated in spermatogenesis. Hum Mol Genet 8:959-969. CrossRef Medline

Venables JP, Dalgliesh C, Paronetto MP, Skitt L, Thornton JK, Saunders PT, Sette C, Jones KT, Elliott DJ (2004) SIAH1 targets the alternative splicing factor T-STAR for degradation by the proteasome. Hum Mol Genet 13:1525-1534. CrossRef Medline

Zheng S, Black DL (2013) Alternative pre-mRNA splicing in neurons: growing up and extending its reach. Trends Genet 29:442-448. CrossRef Medline 